\title{
Nasal CPAP and weight loss in hypertensive patients with obstructive sleep apnoea
}

\author{
Helmuth Rauscher, Dieter Formanek, Wolfgang Popp, Hartmut Zwick
}

\begin{abstract}
Background-The high prevalence of obstructive sleep apnoea (OSA) in patients with systemic hypertension and of hypertension in patients with OSA suggests a causal link between the two disorders. This study was carried out to determine whether nasal continuous positive airway pressure (CPAP) and weight loss affect daytime hypertension in OSA.

Methods-Sixty hypertensive patients with OSA took part in the study; 33 accepted nasal CPAP and used their machine for $5.7(0.2)$ hours per night, and the remaining 27 patients refused nasal CPAP and upper airway surgery so the only therapeutic intervention was a recommendation of weight loss. A significant change in hypertension during follow up was defined as either a change in mean blood pressure of at least $10 \mathrm{~mm} \mathrm{Hg}$ (or more than $8 \%$ ) without a change in drug treatment, or a reduction in drug dosage with mean blood pressure within these limits. Weight loss was defined as a body mass index of at least $5 \%$ below the baseline value.
\end{abstract}

Results-After 512 (41) days, hypertension had become less severe in seven of 12 patients $(58 \%)$ treated with weight loss only, in eight of 28 patients $(29 \%)$ with nasal CPAP only, in two of five patients with nasal CPAP and weight loss, and in one of 15 patients without nasal CPAP or weight loss. Multivariate analysis of variance with the outcome of hypertension at follow up as the dependent variable revealed that only the percentage change in body mass index significantly contributed to the course of hypertension.

Conclusion-The course of hypertension in OSA is more closely linked to weight loss than to elimination of sleep apnoea by nasal CPAP.

(Thorax 1993;48:529-533)

Systemic hypertension is associated with male gender, age and obesity. ${ }^{12}$ As obstructive sleep apnoea (OSA) predominantly occurs in overweight, middle aged men, ${ }^{3-5}$ a close association between hypertension and OSA is not surprising. Extraordinarily high prevalences of hypertension in patients with OSA have been reported, however, ${ }^{67}$ and an elevated apnoea index has been found in up to $48 \%$ of unselected hypertensive patients, ${ }^{8-11}$ so that a causal link between OSA and hypertension has been suggested. The hypothesis that OSA causes hypertension is favoured by reports of blood pressure returning to normal levels after treatment for OSA. ${ }^{12-14}$

If a sleep induced increase in upper airway resistance is a causal factor in the development of hypertension, nasal continuous positive airway pressure (CPAP) should have a beneficial effect on daytime hypertension in these patients. Although there are reports of successful closure of tracheostomy or discontinuation of nasal CPAP after weight loss, ${ }^{15-18}$ a reduction in body weight usually has less impressive effects on OSA, ${ }^{18-21}$ but weight loss is an effective treatment for hypertension. ${ }^{22}$ The aim of this study was therefore to compare the relative contributions of long term nasal CPAP and weight loss on the course of hypertension in patients with OSA.

\section{Methods}

Seventy three consecutive patients with sleep apnoea and a history of hypertension who had been receiving antihypertensive drugs for at least five years were included in the study. All had an apnoea hypopnoea index (AHI) above $10(12 \cdot 6-90)$ and were offered treatment with nasal CPAP. Thirty nine patients accepted nasal CPAP as home therapy, but the other 34 patients refused both nasal CPAP and upper airway surgery so a recommendation of weight loss was the only therapeutic intervention.

Diagnosis of OSA was established by full night polysomnography (PSG) with continuous recording of EEG, EOG, submental EMG, ECG, air flow at nose and mouth (thermistors), movements of rib cage and abdomen (inductance plethysmography or strain gauges), and oxyhaemoglobin saturation. Sleep staging was done according to standard criteria. ${ }^{23}$ Episodes of apnoea were defined as a cessation of airflow at the nose and mouth for longer than 10 seconds. Episodes of hypopnoea were defined as a reduction in rib cage and abdominal movements to $50 \%$ or less compared with the preceding five breaths for longer than 10 seconds accompanied by a fall in arterial oxygen saturation $\left(\mathrm{SaO}_{2}\right)$ to $92 \%$ or lower if baseline was equal to or above $94 \%$; or a fall in $\mathrm{SaO}_{2}$ of $3 \%$ 
or more if baseline was $93 \%$ or lower. The total number of apnoeic and hypopnoeic episodes per hour of sleep represented the AHI. After a mean (SD) of 512 (41) days a follow up PSG was performed, with patients of the nasal CPAP group on the pressure prescribed for home therapy.

Blood pressure was measured on both PSG nights in the sleep laboratory with a standard mercury sphygmomanometer before lights out and immediately after lights on. Measurements were made on both arms in the supine position and the highest value was used for statistical analysis. For the two months before each PSG night, at least two blood pressure readings were available from the patients' general practitioners. These values were also entered into the analysis. Baseline and follow up systolic, mean and diastolic blood pressures were therefore calculated as the means of the laboratory and the general practitioners' readings.

All the patients were on antihypertensive medication. Those nine patients (two from the nasal CPAP group and seven from the non-compliant group) in whom a drug taken at the time of the baseline investigation had been replaced by an alternative drug until follow up were excluded from the analysis. If there was a reduction in the prescribed daily dose of an antihypertensive drug taken at baseline, or if this drug had been omitted until follow up, this was regarded as an improvement of hypertension. By analogy, initiation of an additional antihypertensive drug as well as an increase in the prescribed daily dose was defined as a worsening of hypertension. If the dose of drugs had not been changed since the baseline investigation, a decrease or increase in mean blood pressure of at least $10 \mathrm{~mm} \mathrm{Hg}$, or more than $8 \%$, was defined as a significant change in hypertension.

At follow up, compliance with nasal CPAP was checked by readings of the built in time counter of the patient's device (Sleep Easy II or III, Respironics, Monroeville, Pennsylvania, USA). Only those patients for whom calculation of the time of use per night (hours of operation divided by days since prescription) gave a value higher than four hours were considered compliant with nasal CPAP. A further four patients therefore had to be excluded.

With this method of patient selection there were 33 patients with OSA who were highly compliant with nasal CPAP therapy, indicated by a time of use of $5.7(0.2)$ hours per night, and 27 patients who received no treatment for OSA except the recommendation of weight loss. As only some of the patients

Table 1 Number of patients in groups according to the outcome of hypertension at follow up

\begin{tabular}{lllllll}
\hline & \multicolumn{2}{l}{ Hypertension improved } & & Hypertension \\
\cline { 2 - 5 } & Lower BP & Fewer drugs & Both & $\begin{array}{l}\text { Hypertension } \\
\text { worse }\end{array}$ \\
\hline Nasal CPAP $(\mathrm{n}=33)$ & 6 & 6 & 2 & 2 & 21 \\
Weight loss $(\mathrm{n}=27)$ & 6 & 7 & 5 & 16 & 3 \\
\hline
\end{tabular}

managed to reduce their body weight, the population was further subdivided by weight loss, defined as a decrease in BMI at follow up of more than $5 \%$ from baseline.

\section{STATISTICAL ANALYSIS}

The results are given as means (SE). Comparisons between results of the baseline and the follow up investigation were made by Wilcoxon signed rank test. Analysis of variance (ANOVA) or Mann-Whitney $U$ test were used for comparisons between groups. Correlations were calculated by Spearman's rank test. Statistical significance was assumed at a $p$ value $<0.05$. Determination of variables significantly contributing to the course of hypertension was performed by multivariate ANOVA with the BMDP statistical software package for microcomputers.

\section{Results}

The 60 patients with OSA (48 men and 12 women) included in the analysis had a mean (SD) age of $54.3(1.2)$ years and a mean (SD) AHI of $43 \cdot 1(2 \cdot 8)$. Most were moderately obese, with a mean (SD) BMI of 33.3 (1), ranging from 21 to 60 .

Those 33 patients who accepted nasal CPAP had more severe sleep apnoea than the 27 who refused (AHI 49 (3.6) v 35.9 (3.9); $\mathrm{p}<0.05)$, but there was no difference in BMI $(32.3(1.3) v 34.6(1.4)$ or age $(54(1.8) v$ $54.5(1 \cdot 6)$ years $)$

At follow up the AHI on nasal CPAP $(2.9(2 \cdot 1))$ was within the normal range in the compliant group. In patients not accepting nasal CPAP, the AHI at follow up was not significantly lower than the initial AHI $(34 \cdot 1(2 \cdot 2))$.

Weight loss was recommended to all patients regardless of acceptance of nasal CPAP. There was a small but significant decrease in BMI in the nasal CPAP group (BMI at follow up: $31.7(1.2) ; p<0.05)$ while those who refused nasal CPAP treatment failed to lose weight (BMI at follow-up: $32 \cdot 5(1 \cdot 3))$

The outcome of hypertension at follow up for the two groups is given in table 1 . Hypertension improved in 10 of the 33 patients of the CPAP group and in eight of the 27 patients who refused CPAP, so the percentage of patients who improved was the same in both groups $(30 \%)$. In the CPAP group, those with a fall in blood pressure had higher initial BMI and higher initial blood pressure values than those with equal or higher blood pressure at follow up, but there were no differences in the severity of sleep disordered breathing, efficacy of nasal CPAP in reducing episodes of apnoea, time of nasal CPAP use per night, change in body weight, and age between these subgroups (table 2). In those who refused CPAP initial blood pressure values, AHI, BMI, and age did not differ between those who improved and those who did not, but the former group had a more pronounced decrease in BMI and AHI (table 3). 
Table 2 Mean (SE) characteristics of patients receiving nasal CPAP grouped according to the outcome of hypertension at follow up

\begin{tabular}{|c|c|c|c|}
\hline & $\begin{array}{l}\text { Hypertension } \\
\text { improved } \\
(n=10)\end{array}$ & $\begin{array}{l}\text { Hypertension } \\
\text { unchanged or worse } \\
(n=23)\end{array}$ & $p$ \\
\hline Age & $54(3)$ & $54 \cdot 7(1 \cdot 9)$ & NS \\
\hline Systolic BP (baseline) & $157(4 \cdot 5)$ & $143.9(2 \cdot 7)$ & 0.01 \\
\hline Systolic BP (follow up) & $144(3 \cdot 3)$ & $144 \cdot 1(1 \cdot 6)$ & NS \\
\hline Diastolic BP (baseline) & $91 \cdot 5(2 \cdot 7)$ & $83.5(1 \cdot 3)$ & 0.005 \\
\hline Diastolic BP (follow up) & $84(2 \cdot 1)$ & $81 \cdot 7(1 \cdot 1)$ & NS \\
\hline Mean BP (baseline) & $117 \cdot 7(3)$ & $107 \cdot 7(1 \cdot 6)$ & 0.005 \\
\hline Mean BP (follow up) & $108(2 \cdot 4)$ & $106 \cdot 7(1 \cdot 1)$ & NS \\
\hline AHI (baseline) & $43 \cdot 5(6 \cdot 7)$ & $51 \cdot 4(4 \cdot 8)$ & NS \\
\hline AHI (follow up) & $2 \cdot 6(0.5)$ & $3(0 \cdot 4)$ & NS \\
\hline Change in AHI (\%) & $-93 \cdot 8(1 \cdot 3)$ & $-94 \cdot 3(0 \cdot 8)$ & NS \\
\hline BMI (baseline) & $35.4(1.9)$ & $30.8(0.9)$ & 0.05 \\
\hline BMI (follow up) & $34 \cdot 1(1 \cdot 7)^{\star}$ & $30.6(0.9)$ & NS \\
\hline Change in BMI (\%) & $-3 \cdot 4(1)$ & $-0.3(1.1)$ & NS \\
\hline CPAP per night (hours) & $6 \cdot 1(0 \cdot 3)$ & $5 \cdot 6(0 \cdot 3)$ & NS \\
\hline
\end{tabular}

CPAP_Continuous positive airway pressure; $\mathrm{BP}$ - blood pressure; $\mathrm{AHI}$-apnoea hypopnoea index; BMI-body mass index.

${ }^{\star} \mathrm{p}<0.05$ compared with BMI (baseline).

Table 3 Mean (SE) characteristics of patients who refused nasal CPAP grouped according to the outcome of hypertension at follow up

\begin{tabular}{|c|c|c|c|}
\hline & $\begin{array}{l}\text { Hypertension } \\
\text { improved } \\
(n=8)\end{array}$ & $\begin{array}{l}\text { Hypertension } \\
\text { unchanged or worse } \\
(n=19)\end{array}$ & $p$ \\
\hline Age & $51.8(3.5)$ & $54.9(2 \cdot 1)$ & NS \\
\hline Systolic BP (baseline) & $150(4 \cdot 6)$ & $149 \cdot 7(2.4)$ & NS \\
\hline Systolic BP (follow up) & $141 \cdot 3(3 \cdot 5)$ & $149.5(2.9)$ & NS \\
\hline Diastolic BP (baseline) & $93 \cdot 1(3 \cdot 7)$ & $85 \cdot 3(2)$ & NS \\
\hline Diastolic BP (follow up) & $83.8(1.8)$ & $87 \cdot 1(1 \cdot 5)$ & NS \\
\hline Mean BP (baseline) & $115.9(4)$ & $111 \cdot 7(1 \cdot 8)$ & NS \\
\hline Mean BP (follow up) & $106 \cdot 8(2 \cdot 4)$ & $112 \cdot 1(1 \cdot 8)$ & NS \\
\hline AHI (baseline) & $32 \cdot 5(4 \cdot 6)$ & $37 \cdot 3(4 \cdot 5)$ & NS \\
\hline AHI (follow up) & $25 \cdot 5(5 \cdot 3)$ & $37.7(3.9)$ & NS \\
\hline Change in AHI (\%) & $-21 \cdot 8(11 \cdot 2)$ & $5 \cdot 1(5 \cdot 9)$ & 0.05 \\
\hline BMI (baseline) & $34 \cdot 3(1 \cdot 4)$ & $34 \cdot 6(2 \cdot 5)$ & NS \\
\hline BMI (follow up) & $28.9(1 \cdot 1)^{\star}$ & $34(2 \cdot 4)$ & NS \\
\hline Change in BMI (\%) & $-15 \cdot 3(3.9)$ & $-1 \cdot 1(2 \cdot 1)$ & 0.005 \\
\hline
\end{tabular}

CPAP-Continuous positive airway pressure; $\mathrm{BP}$ - blood pressure; $\mathrm{AHI}$-apnoea hypopnoea index; $\mathrm{BMI}$-body mass index.

${ }^{\star} \mathrm{p}<0.05$ compared with BMI (baseline).

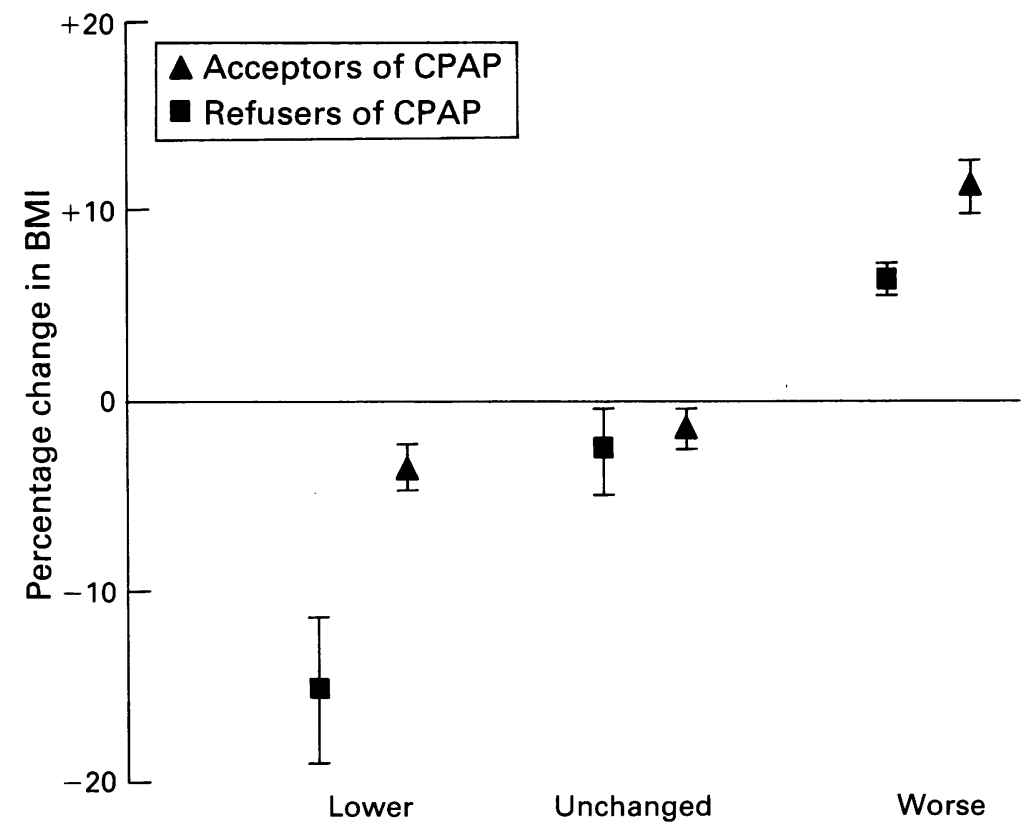

Figure 1 Mean (SD) percentage changes in body mass index (BMI) from baseline to follow up for acceptors and refusers of nasal CPAP in groups according to the outcome of hypertension.
The percentage changes in BMI for patients receiving nasal CPAP with lower, unchanged, and higher blood pressure at follow up are given in fig 1 . There was a trend for patients receiving nasal CPAP with a decrease in blood pressure at follow up to exhibit a slightly more pronounced reduction in body weight. In the non-compliant group the percentage change in BMI between those who improved and those who remained unchanged was significantly different $(p<0.05)$. Because of the small number of patients with an increase in blood pressure at follow up in either group, these were included in the "unchanged" group for statistical analysis. As can be seen from fig 1 , however, all had become more obese since the initial assessment.

Weight loss, as defined, occurred in 12 of the 27 who refused CPAP treatment $(44 \%)$ and in only five patients (15\%) in the nasal CPAP group. The patients therefore fell into four groups: (1) 12 patients with weight loss only; (2) 28 patients receiving nasal CPAP only; (3) five patients with nasal CPAP and weight loss; and (4) 15 patients without nasal CPAP or weight loss. The outcome of hypertension in these groups is shown in fig 2. Hypertension became less severe in seven of the 12 patients $(58 \%)$ with weight loss only, in eight of the 28 patients (29\%) with nasal CPAP only, in two of the five patients with nasal CPAP and weight loss, and in one of the 15 patients without nasal CPAP or weight loss.

The one way ANOVA suggested that initial blood pressure, nasal CPAP use, and changes in BMI contributed significantly to changes in blood pressure in patients compliant with nasal CPAP. In refusers of nasal CPAP only changes in BMI were found to relate to changes in hypertension (table 4). There was, however, a significant correlation between the change in BMI and the change in AHI in refusers of nasal CPAP $(r=0.49$; $\mathrm{p}<0.05$ ). In the nasal CPAP group the influences of nasal CPAP use, as well as of initial blood pressure, disappeared when all the variables were entered into a multivariate ANOVA with hypertension (improved, unchanged, or worse) as the dependent variable, and only the percentage change in BMI predicted a change in hypertension ( $F$ ratio $=$ $13.1 ; p<0.0001)$. The same result was found for refusers of nasal CPAP ( $F$ ratio $=$ $7.6 ; p<0.005$ ). In contrast, in the group that lost weight, initial AHI contributed to the outcome of hypertension, but as in the group that did not lose weight, nasal CPAP did not. For the study population as a whole, again only the percentage change in BMI contributed significantly to the outcome of hypertension at follow up $(F$ ratio $=11.4$; $\mathrm{p}<0.0001$ ).

\section{Discussion}

It has been shown that hypoxaemia as well as exaggerated fluctuations in intrathoracic pressure as a result of snoring or of episodes of 


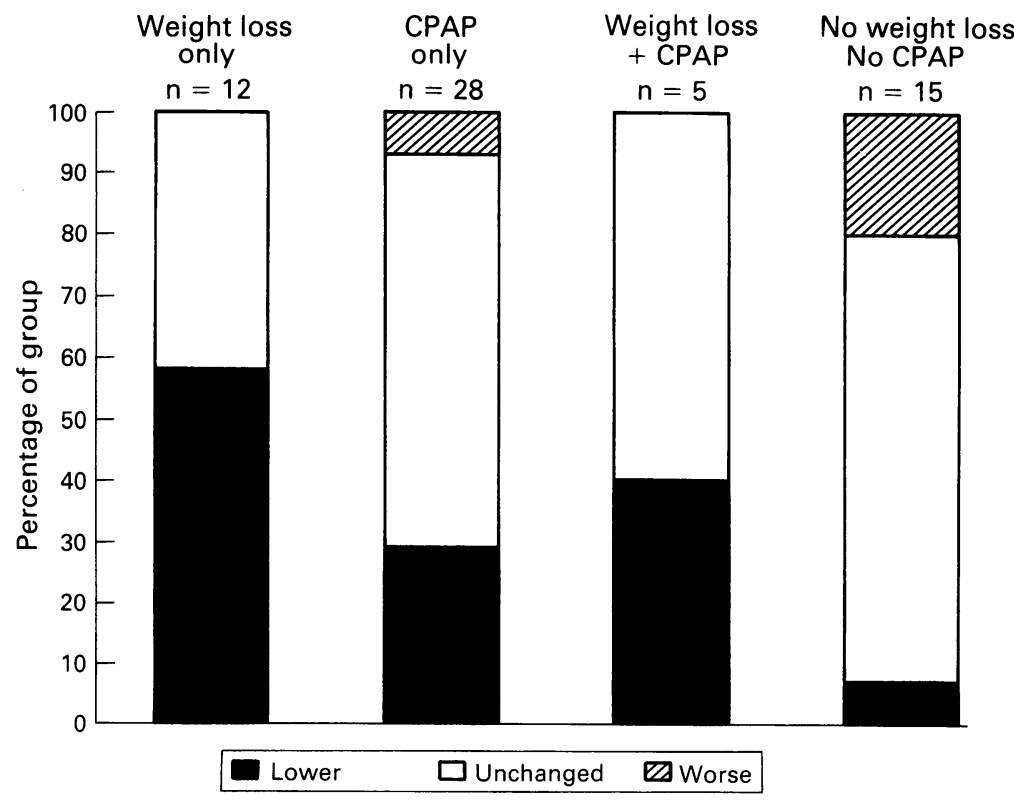

Figure 2 Outcome of hypertension at follow up in acceptors and refusers of nasal CPAP with and without weight loss.
Generally a change in insulin metabolism is thought to be responsible for the association between obesity and hypertension, ${ }^{28} 29$ but the effect of obesity on the upper airway may be equally important. Obesity, by causing pharyngeal fat deposition, can increase upper airway resistance which predisposes to snoring and episodes of apnoea during sleep. ${ }^{30}$ By disturbing sleep architecture, even snoring without apnoeic episodes may cause daytime sleepiness ${ }^{31}$ which, in turn, favours weight gain due to lack of physical activity during the day. This further increase in body weight may worsen upper airway resistance, so that a vicious cycle develops. Assuming that sleep fragmentation resulting from snoring or apnoeic episodes is associated with increased sympathetic activity, this may enhance the development of hypertension. In a recent study ${ }^{32}$ we found elevated but nearly identical prevalences of hypertension in snorers with and without sleep apnoea, suggesting that an obesity induced increase in upper airway resistance even in the absence of OSA may be a risk factor for hypertension.

If increased upper airway resistance during sleep actually contributes to elevated daytime blood pressure, one would expect that nasal CPAP invariably has a beneficial effect on hypertension, but this occurred in less than one third of our patients. Those patients whose hypertension did not improve, however, were obese and had suffered from hypertension for many years, so that structural vascular changes or an obesity related mechanism that does not involve upper airway resistance might have been responsible for the failure of nasal CPAP to reduce daytime blood pressure. The same explanation may be true for refusers of nasal CPAP whose hypertension remained unchanged despite significant weight loss.

As we considered it unethical to recommend weight loss only to refusers of nasal CPAP, weight loss in the group receiving nasal CPAP may have been a confounding factor. If nasal CPAP alone had a beneficial effect on the course of hypertension, however, weight loss in patients receiving nasal CPAP should have enhanced this effect leading to more patients with an improvement of hypertension at follow up in this group compared with the group who refused nasal CPAP. On the other hand, acceptors of nasal CPAP had more severe OSA than refusers. Assuming a

Table 4 Variance ratios $(F)$ and significance values $(p)$ for the outcome of hypertension at follow up as the dependent variable

\begin{tabular}{|c|c|c|c|c|c|c|c|c|}
\hline & \multicolumn{2}{|c|}{$\begin{array}{l}C P A P \\
(n=33)\end{array}$} & \multicolumn{2}{|c|}{$\begin{array}{l}\text { No CPAP } \\
(n=27)\end{array}$} & \multicolumn{2}{|c|}{$\begin{array}{l}\text { Weight loss } \\
(n=17)\end{array}$} & \multicolumn{2}{|c|}{$\begin{array}{l}\text { No weight loss } \\
(n=43)\end{array}$} \\
\hline & $\mathrm{F}$ & $p$ & $\mathrm{~F}$ & $p$ & $\mathrm{~F}$ & $p$ & $\mathrm{~F}$ & $p$ \\
\hline BMI (baseline) & $3 \cdot 48$ & 0.05 & 0.62 & NS & $0 \cdot 39$ & NS & $1 \cdot 92$ & NS \\
\hline Change in BMI (\%) & $13 \cdot 16$ & 0.0001 & $7 \cdot 57$ & 0.005 & 1.99 & NS & $13 \cdot 51$ & 0.00001 \\
\hline Use of CPAP & $4 \cdot 41$ & 0.05 & $1 \cdot 4$ & NS & 0.32 & NS & $2 \cdot 48$ & NS \\
\hline AHI (baseline) & $0 \cdot 42$ & NS & $2 \cdot 63$ & NS & $7 \cdot 68$ & 0.05 & 0.01 & NS \\
\hline Change in $\mathrm{AHI}(\%)$ & 0.91 & NS & $3 \cdot 0$ & NS & $0 \cdot 12$ & NS & $1 \cdot 87$ & NS \\
\hline Mean BP (baseline) & $4 \cdot 97$ & 0.014 & $0 \cdot 64$ & NS & $3 \cdot 38$ & NS & $2 \cdot 56$ & NS \\
\hline
\end{tabular}

BMI-body mass index; CPAP — continuous positive airway pressure; AHI-apnoea hypopnoea index; BP- blood pressure. 
gradual increase in AHI with the time OSA persists, one might hypothesise that, if hypertension parallels OSA, elevated blood pressure also persisted for a longer period of time than in the group who refused CPAP, so reversibility could have been poorer.

Obviously there are some methodological problems that have to be taken into account in interpreting our results. Firstly, all our patients were on antihypertensive drugs so that use of absolute blood pressure values was limited. We therefore had to find a limit for a significant change in measured blood pressure from baseline to follow up which was totally arbitrary. Since lowering the prescribed dose of drugs reflects better control of the hypertensive condition, it appears reasonable also to define a change in the prescribed dose of medication as a response. Secondly, we were unable to monitor compliance with antihypertensive medication so that our results are based solely on prescribed medication. As our patients were on antihypertensive drugs for more than five years, it is unlikely that a relevant change in their compliance with antihypertensive treatment occurred during the study period that could have biased our results. Finally, as blood pressure measurements in the sleep laboratory only provide single points that may not reflect the actual blood pressure during the rest of the day, we tried to minimise this problem by including blood pressure readings by the patients' general practitioners during the two months preceding each sleep study, accepting by this that blood pressure was measured by different subjects with different devices at different times of the day.

In conclusion, the main finding of this study was that the course of hypertension in OSA is more closely linked to changes in body weight than to elimination of apnoeic episodes during sleep by nasal CPAP. Even in those who refused nasal CPAP who lost weight, we failed to find an independent effect of a change in severity of OSA on the course of hypertension. Our findings do not, however, preclude that a reduction in upper airway resistance during sleep either by nasal CPAP or by increasing pharyngeal cross sectional area due to weight loss might have been the common underlying mechanism for the changes in blood pressure observed.

1 Kannel WB, Brand N, Skinner J, Dawber TR, McNamara PM. The relationship of adiposity to blood pressure and development of hypertension. The Framingham study. Ann Intern Med 1967;67:48-59.

2 Miall WE, Lovell HG. Relation between change of blood pressure and age. BMF 1967;ii:660-4.

3 Guilleminault C, Van den Hoed J, Miller MM. Clinical overview of the sleep apnea syndromes. In: Guilleminault C, Dement WC, eds. Sleep apnea syndromes. New York: Alan R Liss, 1978:1-12.

4 Berry DTR, Webb WB, Block AJ. Sleep apnea syndrome: a critical review of the apnea index as a diagnostic criterion. Chest 1984;86:529-31.
5 Harman E, Wynne JW, Block AJ, Molloy-Fisher L. Sleepdisordered breathing and oxygen desaturation in obese patients. Chest 1981;79:256-60.

6 Tilkian AG, Guilleminault C, Schroeder JS, Lehrman KL, Simmons FB, Dement WC. Hemodynamics in sleepinduced apnea studies during wakefulness and sleep. Ann Intern Med 1976;85:714-9.

7 Lugaresi E, Coccagna G, Cirignotta F. Breathing during sleep in man in normal and pathological conditions. Adv Exp Med Biol 1978;99:35-45.

8 Lavie P, Ben Yosef R, Rubin A. Prevalence of sleep apnea syndrome among patients with hypertension. Am Heart f 1984;168:373-6.

9 Kales A, Bixler EO, Cadieux RJ, Schneck DW, Shaw LC, Locke TW, et al. Sleep apnea in a hypertensive population. Lancet 1984;ii:1005-8.

10 Fletcher EC, De Behnke RD, Lovoi MS, Gorin AB. Undiagnosed sleep apnea in patients with essential hypertension. Ann Intern Med 1985;103:190-5.

11 Williams AJ, Houston D, Finberg S, Lam C, Kinney JL, Santiago $S$. Sleep apnea syndromes and essential hypertension. Am f Cardiol 1985;55:1019-22.

12 Burach B, Pollack C, Borowiecki B, Weitzman E. The hypersomnia-sleep apnea syndrome: a reversible major cardiovascular hazard. Circulation 1977;56:(Suppl 3): 177.

13 Motta J, Guilleminault C, Schroeder JS, Dement WC. Tracheostomy and hemodynamic changes in sleepinduced apnea. Ann Intern Med 1978;89:454-8.

14 Staats BA, Offord KP, Richardson JW, Westbrook PR, Fredrickson PA. Long-term follow up of obstructive sleep apnea patients treated with tracheostomy. Sleep Res 1988;17:262.

15 Sugerman HJ, Fairman RP, Lindman AK, Mathers JA, Greenfield LJ. Gastroplasty for respiratory insufficiency of obesity. Ann Surg 1981;193:677-85.

16 Victor DW, Sarmiento CF, Yanta M, Halverson JD. Obstructive sleep apnea in the morbidly obese. An indication for gastric bypass. Arch Surg 1984;119:970-2.

17 Charuzi I, Peiser J, Ovnat A, Lavie P. Removal of tracheostomy in a morbidly obese sleep apnea patient after gastric bypass. Sleep 1986;9:449-50.

18 Aubert-Tulkens G, Culee C, Rodenstein DO. Cure of sleep apnea syndrome after long-term nasal continuous positive airway pressure therapy and weight loss. Sleep 1989;12:216-22.

19 Harman EM, Wynne JW, Block AJ. The effect of weight loss on sleep disordered breathing and oxygen desaturation in morbidly obese men. Chest 1982;82:291-4.

20 Suratt PM, McTier R, Findley LJ, Pohl SL, Wilhoit SC. Changes in breathing and the pharynx after weight loss in obstructive sleep apnea. Chest 1987;92:631-7.

21 Smith PL, Gold AR, Meyers DA, Haponik EF, Bleecker ER. Weight loss in mildly to moderately obese patients with obstructive sleep apnea. Ann Intern Med 1985;103:850-5.

22 Hovell MF. The experimental evidence for weight-loss treatment of essential hypertension: a critical review. Am $\mathcal{F}$ Public Health 1982;72:359-68.

23 Rechtschaffen A, Kales A. A manual of standardized terminology techniques and scoring systems for sleep stages of human subjects. Washington, DC: National Institute of human subjects. Washingto

24 Tilkian AG, Guilleminault C, Schroeder JS, Lehrman KL, Simmons FB, Dement WC. Hemodynamics in sleepinduced apnea: studies during wakefulness and sleep. Ann Intern Med 1976;85:714-9.

25 Goldstein DS. Plasma catecholamines and essential hypertension. Hypertension 1983;5:86-99.

26 Oparil S. The sympathetic nervous system in clinical and experimental hypertension. Kidney Int 1986;30:437-52.

27 Hoffstein V, Rubinstein I, Mateika S, Slutskey AS. Determinants of blood pressure in snorers. Lancet 1988;ii:992-4.

28 Modan M, Halkin H, Almog S, Lusky A, Eshkol A, Shefi $M$, et al. Hyperinsulinemia: a link between hypertension, obesity, and glucose intolerance. $¥$ Clin Invest sion, obesity, and

29 Halverson JD, Kramer J, Cave A, Permutt A, Santiago J. Altered glucose tolerance, insulin response and insulin sensitivity after massive weight reduction subsequent to gastric bypass. Surgery 1982;92:235-40.

30 Katz I, Stradling J, Slutsky AS, Zamel N, Hoffstein V. Do patients with obstructive sleep apnea have thick necks? Am Rev Respir Dis 1990;141:1228-31.

31 Guilleminault C, Stoohs R, Duncan S. Snoring (I): Daytime sleepiness in regular heavy snorers. Chest 1991; 99:40-8.

32 Rauscher H, Popp W, Zwick H. Systemic hypertension in snorers with and without sleep apnea. Chest 1992;102: 367-71. 